\title{
BMP-2-COATED MINERAL COATED MICROPARTICLES IMPROVE BONE REPAIR IN ATROPHIC NON-UNIONS
}

\author{
M. Orth ${ }^{1,2, *}$, N.J. Kruse ${ }^{1,2}$, B.J. Braun ${ }^{1,2}$, C. Scheuer ${ }^{2}$, J.H. Holstein ${ }^{1,2}$, A. Khalil ${ }^{3}$, X. Yu ${ }^{3}$, W.L. Murphy ${ }^{3}$, \\ T. Pohlemann ${ }^{1}$, M.W. Laschke ${ }^{2}$ and M.D. Menger ${ }^{2}$
${ }^{1}$ Department of Trauma, Hand and Reconstructive Surgery, Saarland University, Homburg, Germany
${ }^{2}$ Institute of Clinical and Experimental Surgery, Saarland University, Homburg, Germany
${ }^{3}$ Department of Biomedical Engineering, University of Wisconsin-Madison, Madison, USA

\begin{abstract}
Atrophic non-unions are a major clinical problem. Mineral coated microparticles (MCM) are electrolyte-coated hydroxyapatite particles that have been shown in vitro to bind growth factors electrostatically and enable a tuneable sustained release. Herein, we studied whether MCM can be used in vivo to apply Bone Morphogenetic Protein-2 (BMP-2) to improve bone repair of atrophic non-unions. For this purpose, atrophic non-unions were induced in femurs of CD-1 mice $(n=48)$. Animals either received BMP-2-coated MCM (MCM + BMP; $n=16)$, uncoated MCM (MCM; $n=16)$ or no MCM (NONE; $n=16)$. Bone healing was evaluated 2 and 10 weeks postoperatively by micro-computed tomographic $(\mu \mathrm{CT})$, biomechanical, histomorphometric and immunohistochemical analyses. $\mu \mathrm{CT}$ revealed more bone volume with more highly mineralised bone in MCM + BMP femurs. Femurs of MCM + BMP animals showed a significantly higher bending stiffness compared to other groups. Histomorphometry further demonstrated that the callus of MCM + BMP femurs was larger and contained more bone and less fibrous tissue. After 10 weeks, 7 of $8 \mathrm{MCM}+\mathrm{BMP}$ femurs presented with complete osseous bridging, whereas NONE femurs exhibited a non-union rate of $100 \%$. Of interest, immunohistochemistry could not detect macrophages within the callus, indicating a good biocompatibility of MCM. In conclusion, the local application of BMP-2coated MCM improved bone healing in a challenging murine non-union model and, thus, should be of clinical interest in the treatment of non-unions.
\end{abstract}

Keywords: Non-union, mineral coated microparticles, BMP-2, bone healing, biocompatibility, mice

*Address for correspondence:

Marcel Orth, M.D.

Department of Trauma, Hand and Reconstructive Surgery

Saarland University

Kirrberger Strasse 1

D-66421 Homburg/Saar

Germany

Telephone: +4968411631502

Fax: +4968411631503

Email: marcel.orth@uks.eu
Table 1: List of abbreviations used in text, tables and figures.

\begin{tabular}{|l|l|}
\hline $\mathrm{BMD}$ & bone mineral density \\
\hline $\mathrm{BMD}_{\text {high }}$ & bone mineral density for highly mineralised bone \\
\hline $\mathrm{BMD}_{\text {low }}$ & bone mineral density for poorly mineralised bone \\
\hline $\mathrm{BMP} 2$ & Bone Morphogenetic Protein-2 \\
\hline $\mathrm{BV}_{\text {high }}$ & highly mineralised bone volume \\
\hline $\mathrm{BV}_{\text {low }}$ & poorly mineralised bone volume \\
\hline $\mathrm{BV}_{\text {total }} / \mathrm{TV}$ & bone volume fraction of tissue volume \\
\hline $\mathrm{cb}$ & cortical bone \\
\hline $\mathrm{ch}$ & clip hole \\
\hline $\mathrm{ct}$ & cartilage tissue \\
\hline $\mathrm{ft}$ & fibrous tissue \\
\hline $\mathrm{HE}$ & haematoxylin and eosin \\
\hline $\mathrm{HEPES}$ & hydroxyethyl-piperazineethanesulphonic acid \\
\hline $\mathrm{MCM}$ & mineral coated microparticles \\
\hline$\mu \mathrm{CT}$ & micro-computed tomography \\
\hline $\mathrm{mSBF}$ & modified simulated body fluid \\
\hline $\mathrm{PBS}$ & phosphate buffer solution \\
\hline $\mathrm{ROI}$ & region of interest \\
\hline rh & recombinant human \\
\hline rpm & revolutions per minute \\
\hline $\mathrm{SEM}$ & standard error of the mean \\
\hline
\end{tabular}

\section{Introduction}

Despite the growing knowledge on the mechanisms of bone repair, inadequate fracture healing remains a substantial clinical problem. Approximately $10 \%$ of all fractures result in delayed fracture healing or non-unions (Einhorn and Gerstenfeld, 2015). While most hypertrophic non-unions can be successfully treated with stable osteosynthesis, the treatment of atrophic non-unions is often difficult and highly challenging (Megas, 2005). Aetiologically, atrophic non-unions are multifactorial (Garcia et al., 2008a). One of the main causes is a deficient osteogenesis (Kanczler and Oreffo, 2008). The gold standard in the treatment of non-unions is autogenous transplantation of bone (Tang et al., 2012). However, significant problems as e.g. limited supply and donor-site morbidity restrict its use (Yoneda et al., 2005). Alternative treatment options such as allogenic bone transplantation are associated with other risks, including immune responses and transmission of diseases and infections (Bauer and Mutschler, 2000).

Lately, multiple carrier systems have been introduced to apply angiogenic and osteogenic growth factors in order to circumvent these limitations. Unfortunately, initial burst releasing systems could not show any significant 
improvements in bone healing (King and Krebsbach, 2012; Einhorn, 2003). Subsequently introduced carrier systems, such as e.g. hydrogels or nanoparticles, enabled a sustained release of growth factors (Burdick et al., 2002; Ghosh et al., 2008). In order to control and tune the release of growth factors according to individual needs, sophisticated delivery systems such as mineral coated microparticles (MCM) have recently been developed (Yu et al., 2014). MCM are electrolyte-coated hydroxyapatite particles that are able to bind growth factors, such as Bone Morphogenetic Protein-2 (BMP-2).

Bone morphogenetic proteins have been shown to play an important role in fracture healing (Mi et al., 2013). BMP-2 is a member of the transforming growth factor- $\beta$ superfamily and induces bone formation in vivo (Huang et al., 2008). BMP-2 plays a crucial role in the signalling cascade in human fracture callus. Its expression is significantly reduced in cartilaginous tissue of non-unions compared to that of normal healing fractures (Kloen et al., 2003; Kwong et al., 2009). BMP-2 acts during the early stage of fracture healing by promoting differentiation of mesenchymal stem cells and osteoprogenitor cells into osteoblasts (Mi et al., 2013; Cheng et al., 2003). Numerous studies using in vitro, ex vivo and in vivo settings have investigated the molecular pathways of BMP-2, demonstrating a triggering function of osteogenesis through various autocrine and paracrine regulatory mechanisms, such as the BMP/Smad-pathway (Mi et al., 2013; Huang et al., 2008; Cheng et al., 2003; Tsuij et al., 2006; Turgemann et al., 2001; Zegzula et al., 1997; Gazit et al., 1999; Ten Dijke et al., 2006).

In vitro, binding and release kinetics of MCM have been analysed for BMP-2 in detail. While BMP-2 binding is linear to the BMP-2 dosage used for incorporation of the growth factor, the release profile is dependent on the composition of the electrolyte coating (Yu et al., 2014). In vivo, however, the action of BMP-2-coated MCM has not been studied yet. Therefore, we herein analysed for the first time whether BMP-2-coated MCM can improve bone repair in atrophic non-unions in vivo. We studied this hypothesis in a well-established murine model of an atrophic nonunion in femurs using radiological, biomechanical, histomorphometric and immunohistochemical techniques.

\section{Materials and Methods}

\section{Preparation and characterisation of MCM}

To prepare the MCM for coating, $100 \mathrm{mg}$ of hydroxyapatite particles were incubated in $50 \mathrm{~mL}$ of modified simulated body fluid (mSBF) at $37^{\circ} \mathrm{C}$ for $7 \mathrm{~d}$ as described previously (Yu et al., 2014). The mSBF was changed daily in order to maintain consistent ion concentrations for mineral coating growth. The ionic composition of $\mathrm{mSBF}$ is described in Table 2 .

The $\mathrm{pH}$ of $\mathrm{mSBF}$ was adjusted to 6.8 by using $\mathrm{HCl} /$ $\mathrm{NaOH}$. After the coating process MCM were rinsed with deionised water and lyophilised. The morphology and composition of the MCM were examined by scanning electron microscopy. The surface morphology of the MCM was analysed by a LEO 1530 field emission scanning microscopy (Zeiss, Jena, Germany) after sputter coating with gold.

\section{Binding and release kinetics of $\mathrm{MCM}$}

To determine the binding and release profile of MCM, radiolabelled BMP-2 ( ${ }^{125} \mathrm{I}$-labelled BMP-2, Perkin Elmer, Waltham, MA, USA) was used as described previously (Yu et al., 2014). Briefly, $5 \mathrm{mg}$ of electrolyte-coated MCM were incubated in $1 \mathrm{~mL}$ solution with $16 \mu \mathrm{g} / \mathrm{mL}$ BMP-2 (0.5\% ${ }^{125}$ I-BMP-2, Perkin Elmer, Waltham, MA, USA) in phosphate buffer solution (PBS) at $37{ }^{\circ} \mathrm{C}$ for $4 \mathrm{~h}$ with rotation. The MCM were then centrifuged at 12,000 rpm for 2 min and washed once with $1 \mathrm{~mL}$ PBS. The radioactivity in the supernatant and washing PBS was measured by a Packard Cobra II gamma counter (Perkin Elmer, Waltham, MA, USA) to determine the BMP-2 amount in these solutions. The binding efficiency of the microparticles was calculated from the protein concentration change before and after binding.

For BMP-2 release, the BMP-2-coated MCM (5 mg) of the binding assays were incubated in $1 \mathrm{~mL} \mathrm{mSBF}$ (pH 7.4) at $37^{\circ} \mathrm{C}$ and the released protein amount was determined by measuring the radioactivity of the release medium using the gamma counter at predetermined time points.

For the in vivo experiments in mice, MCM were coated with rhBMP-2 (eBioscience, Affymetrix, Santa Clara, CA, USA) by incubating $2 \mathrm{mg}$ MCM in $2 \mathrm{~mL}$ PBS containing $20 \mu \mathrm{g} / \mathrm{mL} \mathrm{BMP}-2$ at $37^{\circ} \mathrm{C}$ for $4 \mathrm{~h}$ with rotation. The MCM were centrifuged for $3 \mathrm{~min}$ and then washed with PBS once.

\section{Animals}

We used 9 to 14 weeks old CD-1 mice with a mean body weight of $35 \pm 3 \mathrm{~g}$. The animals were bred at the Institute of Clinical and Experimental Surgery, Saarland University, Homburg/Saar, Germany. The animals were kept at a $12 / 12 \mathrm{~h}$ light and dark cycle and had access to tap water and standard pellet food (Altromin, Lage, Germany) ad libitum. The study was conducted in accordance with the German legislation on protection of animals and the NIH guidelines for the care and use of laboratory animals and has been approved by the local governmental animal care committee.

Table 2: Ionic composition of modified simulated body fluid. The mSBF includes ions in a welldefined composition and is buffered by hydroxyethyl-piperazineethanesulphonic acid (HEPES).

\begin{tabular}{|c|c|c|c|c|c|c|c|c|c|}
\hline \multicolumn{10}{|c|}{ mSBF } \\
\hline Ion & $\mathrm{HCO}_{3}^{-}$ & $\mathrm{NaCl}$ & $\mathrm{KCl}$ & $\mathrm{MgSO}_{4}$ & $\mathrm{MgCl}_{2}$ & $\mathrm{NaHCO}_{3}$ & $\mathrm{HEPES}$ & $\mathrm{CaCl}_{2}$ & $\mathrm{KH}_{2} \mathrm{PO}_{4}$ \\
\hline Amount $(\mathrm{mM})$ & 4.2 & 141.0 & 4.0 & 0.5 & 1.0 & 4.2 & 20.0 & 5.0 & 2.0 \\
\hline
\end{tabular}




\section{Surgical Procedure}

Femoral atrophic non-unions were induced in CD-1 mice $(n=48)$ by creating a segmental bone defect, which was stabilised using the pin-clip technique as described previously in detail (Garcia et al., 2008a). Briefly, animals were anaesthetised by an intraperitoneal injection of $25 \mathrm{mg}$ / $\mathrm{kg}$ Xylazine (Bayer, Leverkusen, Germany) and $75 \mathrm{mg} / \mathrm{kg}$ Ketamine (Serumwerk Bernburg AG, Bernburg, Germany). Under aseptic conditions an approximately $4 \mathrm{~mm}$ medial parapatellar incision was performed at the right knee and the patella was dislocated laterally. After inducing a hole (diameter $0.5 \mathrm{~mm}$ ) into the intercondylar notch, a distally flattened 24 Gauge needle (diameter $0.55 \mathrm{~mm}$ ) was implanted intramedullary. The pin was flattened at the distal end to avoid secondary pin dislocation. After insertion of the pin, the diaphysis of the femur was exposed by a lateral approach. Then, a custom-made clip of $6 \mathrm{~mm}$ length was implanted ventro-dorsally into the femur and lateral of the already implanted pin. Subsequently, an osteotomy with a gap size of $1.8 \mathrm{~mm}$ was created under permanent saline cooling between the two brackets of the metallic clip using size-standardised spherical trephines. The gap sizes were controlled by custom-made templates. The metallic clip inserted before creation of the gap guaranteed that the gap size was maintained. Moreover, the periosteum was stripped $2 \mathrm{~mm}$ proximally and distally of the gap along the longitudinal axis of the femoral bone. All procedures were done under an operating microscope, resulting in a high level of precision. The group NONE $(n=16)$ did not receive microparticles, leaving the osteotomy gap blank. In the group MCM $(n=16) 2 \mathrm{mg}$ of uncoated MCM were implanted into the osteotomy gap by direct injection with a $10 \mu \mathrm{L}$ syringe under visual control. The animals of the group MCM + BMP $(n=16)$ received also by direct injection MCM coated with approximately $13.7 \mu \mathrm{g}$ BMP-2/ mg MCM. The dosage of BMP-2 was chosen based upon pre-experiments and an extensive literature search (Saito et al., 2003; Schmidmaier et al., 2002; Suárez-González et al., 2014; Kanczler et al., 2010). Finally, wound closure completed the surgical procedure.

Animals were killed at 2 ( $n=8$ each group) and 10 weeks ( $n=8$ each group) after surgery by an overdose of barbiturates. Prior to sacrifice, X-rays of the operated femurs were taken to exclude secondary dislocation of the metallic implants. Then, femurs were harvested to investigate bone healing by micro-computed tomography $(\mu \mathrm{CT})$ as well as by biomechanical, histomorphometric and immunohistochemical analyses.

\section{$\mu \mathrm{CT}$}

The specimens ( $n=8$ per group) were scanned (Skyscan 1172, Bruker, Billerica, MA, USA) at a spatial resolution of $8.9 \mu \mathrm{m}$ (tube voltage: $50 \mathrm{kV}$; current: $200 \mu \mathrm{A}$; intervals: $0.4^{\circ}$; exposure time: $2400 \mathrm{~ms}$; filter: $0.5 \mathrm{~mm}$ aluminium). Images were stored in three-dimensional arrays. To express grey values as mineral content (bone mineral density; BMD), calcium hydroxyapatite (CaHA) phantom rods with known BMD values (0.250 g and $0.750 \mathrm{~g} \mathrm{CaHA} /$ $\mathrm{cm}^{3}$ ) were employed for calibration. The region of interest (ROI) defining the novel bone was contoured manually excluding any original cortical bone as well as the microparticles. In order to exclude MCM and soft tissue from bone tissue, the ROI was processed with a threshold procedure (CTAnalyser, Bruker, Billerica, MA, USA). The thresholding also allowed the differentiation between highly and poorly mineralised bone. The thresholds to distinguish between highly and poorly mineralised bone were based upon visual inspection of the images, qualitative comparison with histological sections and other studies investigating bone repair and callus tissue by $\mu \mathrm{CT}$ (Bosemark et al., 2013; Morgan et al., 2009; Isaksson et al., 2009). A BMD with more than $0.642 \mathrm{~g} / \mathrm{cm}^{3}$ resulting in grey values of $98-255$ was defined as highly mineralised bone. Poorly mineralised bone was assumed to have a BMD value between $0.410 \mathrm{~g} / \mathrm{cm}^{3}$ and $0.642 \mathrm{~g} / \mathrm{cm}^{3}$ resulting in grey values of 68-97. MCM had a mean grey value of $37.8( \pm 0.02)$ resulting in $99.96 \%$ of MCM having a grey value under the lower threshold of 68 .

The following parameters were calculated from the callus region of interest for each specimen: highly mineralised bone volume $\left(\mathrm{BV}_{\text {high }}\right)$, poorly mineralised bone volume $\left(\mathrm{BV}_{\text {low }}\right)$, bone volume fraction of tissue volume $\left(\mathrm{BV}_{\text {total }} / \mathrm{TV}\right)$ and average bone mineral density for highly and poorly mineralised bone $\left(\mathrm{BMD}_{\text {high }}\right.$ and $\left.\mathrm{BMD}_{\text {low }}\right)$. The BMD was calculated by using the voxels within the aforementioned thresholds.

\section{Biomechanical analysis}

Bending stiffness was measured by a 3 point bending device (Mini-Zwick Z 2.5, Zwick, Ulm, Germany) using a non-destructive approach (Histing et al., 2016). This allowed us to use the specimens also for the histological and immunohistochemical investigations and, thus, to reduce the number of laboratory animals needed.

\section{Histology and histomorphometry}

After biomechanical testing, bones were fixed in $4 \%$ phosphate buffered formalin for $24 \mathrm{~h}$, decalcified in $13 \%$ EDTA solution for 3 weeks and then embedded in paraffin. For histomorphometric analysis, longitudinal sections of $5 \mu \mathrm{m}$ thickness were stained according to the trichrome Masson Goldner method. At a magnification of 12.5× (Olympus BX60 Microscope, Olympus, Shinjuku, Japan; Zeiss Axio Cam and Axio Vision 3.1, Zeiss) structural indices were calculated according to the recommendations of Gerstenfeld et al. (2005). The following histomorphometric parameters were evaluated: (i) total periosteal callus area; (ii) bone callus area; (iii) cartilaginous callus area; (iv) fibrous callus area. The total periosteal callus area was defined as all osseous, cartilaginous and fibrous callus tissue between the two drilling holes of the clip outside of the cortices. Pre-existing cortical bone of the proximal and distal fragment, however, was excluded. Each area was marked and calculated using the ImageJ analysis system (NIH, Bethesda, USA). We assessed only periosteal callus area, because endosteal callus formation might have been affected by the intramedullary implant.

In addition, a scoring system (modified Goldberg Score) was used to evaluate the quality of gap bridging as described previously (Garcia et al., 2008a; Holstein et al., 2011). Both cortices were analysed regarding osseous 

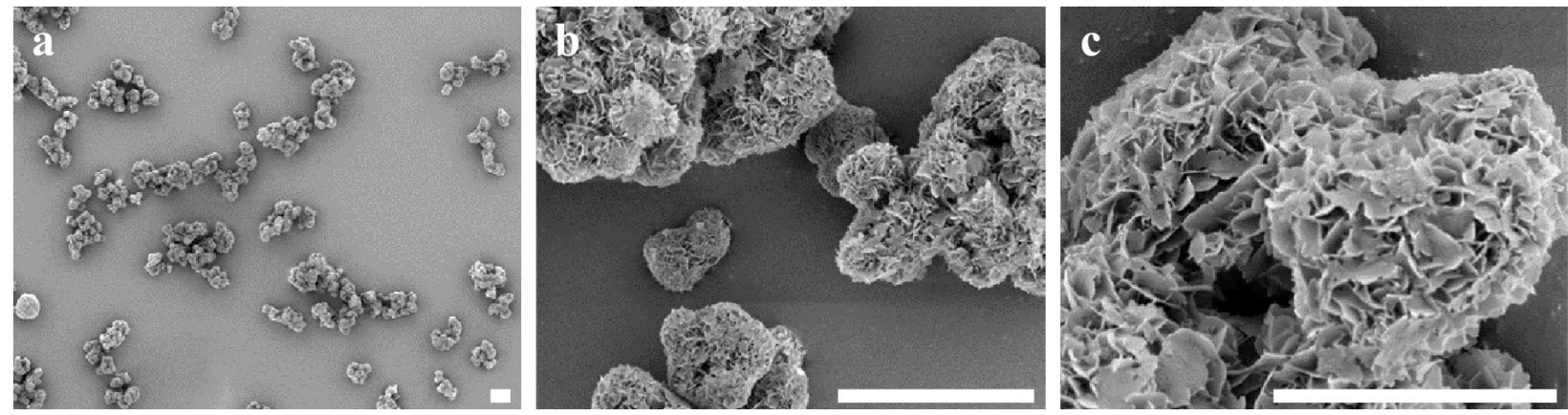

Fig. 1. (a-c) Scanning electron microscopic images of MCM in different magnifications after sputter coating with gold revealing a typical plate-like structure of the mineral coating. The average size of the nano-scale plates is approximately $1 \mu \mathrm{m}$. The scale bars represent $5 \mu \mathrm{m}$.

bridging ( 2 points), cartilage bridging (1 point) or bridging by fibrous tissue ( 0 points). This scoring system allowed a maximum of 4 points, indicating complete bone bridging and a minimum of 0 points, indicating lack of bone healing.

In order to evaluate if MCM could be detected within the osteotomy gap at 2 weeks and 10 weeks after surgery, $5 \mu \mathrm{m}$ sections were additionally cut and stained with haematoxylin and eosin (HE) according to standard procedures.

\section{Immunohistochemistry}

In order to analyse the biocompatibility of MCM in vivo, we performed immunohistochemical staining of macrophages by using a rabbit polyclonal anti-F4/80 antibody as primary antibody (1:50; ab111101, Abcam, Cambridge, UK). This was followed by a biotinylated goat anti-rabbit IgG antibody (ready-to-use; ab64256, Abcam). 3,3'-diaminobenzidine (D4168, Sigma-Aldrich, St. Louis, USA:) was used as chromogen. The sections were counterstained with Mayer's haemalum (1.09249.1000, Merck, Darmstadt, Germany) and examined by light microscopy (Olympus BX60; Olympus, Shinjuku, Japan). Immunohistochemically stained sections from mouse lungs served as positive control for the detection of F4/80positive alveolar macrophages. Sections without incubation with the primary antibody against $F 4 / 80$ served as negative controls.

\section{Statistical analyses}

All data are given as means \pm standard error of the mean (SEM). First, data were tested for normal distribution and equal variance. In case of parametric data, comparisons between the experimental groups were performed by oneway ANOVA followed by a Holm Sidak test for all pairwise comparisons, including the correction of the $\alpha$-error according to Bonferroni probabilities. In case of nonparametric data, comparisons between the experimental groups were performed by one-way ANOVA on ranks followed by a Dunn's test for all pairwise comparisons, which also included a correction of the $\alpha$-error according to Bonferroni probabilities. The statistical analyses were performed using the SigmaPlot software 11.0 by Systat software (San Jose, USA). A $p$-value $<0.05$ was considered to indicate significant differences.

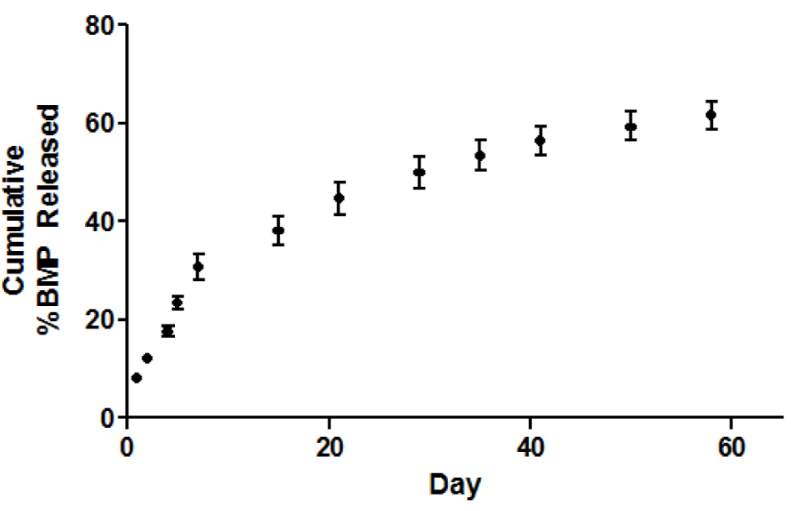

Fig. 2. Sustained release of BMP-2 from MCM analysed over $60 \mathrm{~d}$. The profile revealed a release after $7 \mathrm{~d}$ of $30.8 \%( \pm 1.5 \%)$ of the bound BMP-2. After $30 \mathrm{~d} 49.9 \%$ $( \pm 1.8 \%)$ of the bound BMP-2 was released. After $60 \mathrm{~d}$ a total release of $61.7 \%( \pm 1.7 \%)$ was observed. Mean $\pm \operatorname{SEM}(n=3)$.

\section{Results}

\section{Characterisation of MCM}

The scanning electron microscopy images of MCM revealed a uniform layer of mineral coating with a typical plate-like structure after incubating hydroxyapatite particles in mSBF for $7 \mathrm{~d}$ (Fig. 1). As described by Yu et al. (2014), the size of the nano-scale plates is dependent on the concentration of $\mathrm{HCO}_{3}^{-}$in $\mathrm{mSBF}$. Using $4.2 \mathrm{mM}$ $\mathrm{HCO}_{3}^{-}$in this study, the morphology of MCM with a size of the nano-scale plates of approximately $1 \mu \mathrm{m}$ was comparable to previous results.

\section{Binding and release kinetics of MCM}

The binding efficiency of MCM used in this study was $68.6 \%( \pm 1.1 \%)$ of the concentration of the incorporating solution. The release profile revealed an initial minor burst release, followed by a sustained release. After $60 \mathrm{~d} 61.7 \%$ of the bound growth factor had been released (Fig. 2).

\section{$\mathrm{X}$-ray and $\mu \mathrm{CT}$}

The X-rays taken prior to sacrificing showed no osseous bridging in animals of the groups NONE and MCM, while animals of MCM + BMP demonstrated a callus formation after 2 weeks and osseous bridging after 10 weeks (Fig. 3). Of interest, callus formation in the MCM + BMP group 
was not evenly distributed around the femoral cortices but tended to develop on the dorsal side of the femur (Fig. 3e). This observation may be due to the fact that the structure of the clip allowed more interfragmentary movement between the clip legs at the dorsal side of the femur, which, in turn, promoted endochondral ossification and, thus, more callus formation.

The $\mu \mathrm{CT}$ analysis revealed a significantly increased formation of highly and poorly mineralised bone volume after 2 weeks and 10 weeks in the group MCM + BMP compared to MCM and NONE. Whereas the total bone volume was reduced after 10 weeks compared to 2 weeks, the highly mineralised bone volume was higher after 10 weeks. $\mathrm{BV}_{\text {total }} / \mathrm{TV}$ was significantly higher in the group $\mathrm{MCM}+\mathrm{BMP}$ compared to the MCM and NONE groups after 2 weeks and compared to MCM after 10 weeks (Fig. 4). $\mathrm{BMD}_{\text {high }}$ and $\mathrm{BMD}_{\text {low }}$ were not significantly different at 2 weeks and 10 weeks between MCM + BMP, MCM and NONE (data not shown).

\section{Biomechanical analysis}

Femurs of MCM + BMP animals exhibited a significantly higher bending stiffness after 2 weeks as well as after 10 weeks (Table 3 ). In fact, the femurs of the MCM and NONE groups showed practically no bending stiffness at 2 weeks and 10 weeks, which indicates non-union formation. In contrast, femurs of the MCM + BMP group revealed an increasing bending stiffness over the 10 weeks period, which indicates bone repair (Table 3). However, the bending stiffness in the group MCM + BMP was only $36 \%$ of that measured for non-fractured femurs $(47.7 \pm 4.9 \mathrm{~N} /$ $\mathrm{mm})$.

\section{Histomorphometric analysis}

HE staining of sections after 2 weeks and 10 weeks revealed that MCM could still be detected at the site of implantation, proving that MCM had not dissolved during the study period (Fig. 5). Moreover, many MCM accumulated to larger aggregates over time (Fig. 5).

At 2 weeks after surgery the modified Goldberg score demonstrated an improved bridging of the osteotomy gap of MCM + BMP femurs compared to MCM and NONE femurs. At 10 weeks, 7 of 8 specimens of the MCM + BMP group exhibited complete osseous bridging, while only 2 of 8 specimens of the group MCM and 0 of 8 specimens of the group NONE showed osseous bridging (Table 3 ).

At 2 weeks and 10 weeks after surgery the femurs of $\mathrm{MCM}+\mathrm{BMP}$ animals exhibited a significantly larger total periosteal callus area compared to the femurs of MCM
2 weeks

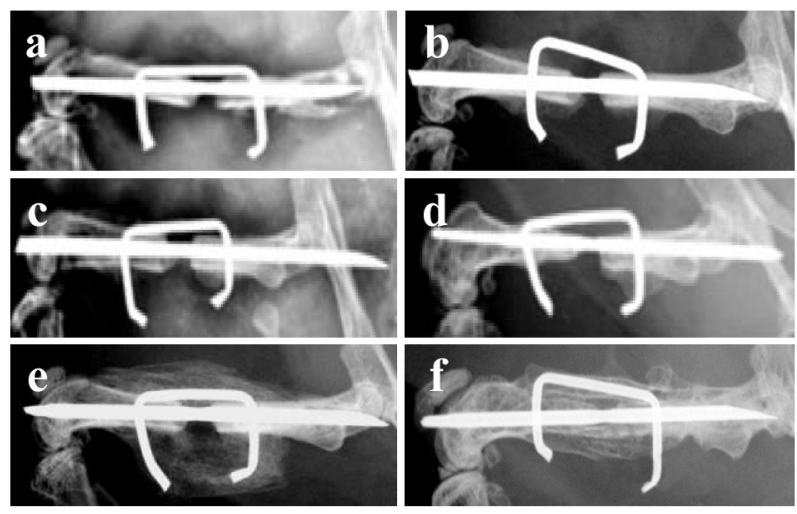

Fig. 3. X-rays of the osteotomised mouse femur with a segmental defect of $1.8 \mathrm{~mm}$ stabilised by the pinclip technique 2 weeks (a,c,e) and 10 weeks $(\mathbf{b}, \mathbf{d}, \mathbf{f})$ postoperatively. NONE (a,b) and MCM (c,d) did not show osseous bridging, indicating non-unions, while MCM + BMP showed a callus formation after 2 weeks (e) and osseous bridging after 10 weeks (f).

and NONE animals (Fig. 6). In addition, analysis of the callus composition showed a greater fraction of bone and a smaller fraction of fibrous tissue in MCM + BMP femurs after 2 weeks and 10 weeks (Fig. 6i, j). After 10 weeks, no cartilage tissue was detectable in the callus of MCM + BMP femurs, while some femurs of the MCM + BMP group showed complete remodelling at this time point (Fig. $6 \mathbf{f})$.

\section{Immunohistochemical analysis}

Additional immunohistochemical analyses of the bone defects in all groups, which had received microparticles, showed that MCM did not induce a relevant inflammatory response. In fact, F4/80 positive macrophages were only rarely detected in direct vicinity to $\mathrm{MCM}$ and $\mathrm{MCM}$ aggregates, indicating a good biocompatibility (Fig. 7).

\section{Discussion}

The present study is the first demonstration to use MCM as therapeutic delivery carrier for non-union healing. The results of the study confirmed our hypothesis that the treatment with BMP-2-coated MCM is capable of improving bone repair in atrophic non-unions in mice.

Table 3: Biomechanical analysis and histomorphometric evaluation of callus bridging. The group NONE received no MCM, the group MCM received uncoated MCM (2 mg MCM/ non-union) and the group MCM + BMP received BMP-2-coated MCM (13.7 $\mu \mathrm{g}$ BMP-2/mg $\mathrm{MCM} ; 2 \mathrm{mg} \mathrm{MCM} /$ non-union). Mean $\pm \mathrm{SEM}$; ${ }^{\mathrm{a}} p<0.05$ vs. NONE and MCM.

\begin{tabular}{|c|c|c|c|c|}
\hline & Group & NONE & MCM & MCM + BMP \\
\hline \multirow{2}{*}{ 2 weeks } & Biomechanical analysis (N/mm) & $0.1 \pm 0.01$ & $0.2 \pm 0.01$ & $2.2 \pm 0.4^{\mathrm{a}}$ \\
\cline { 2 - 5 } & Modified Goldberg Score & $0 \pm 0$ & $0 \pm 0$ & $2.4 \pm 0.2^{\mathrm{a}}$ \\
\hline \multirow{2}{*}{$\mathbf{1 0}$ weeks } & Biomechanical analysis (N/mm) & $0.9 \pm 0.6$ & $0.4 \pm 0.3$ & $17.2 \pm 7.9^{\mathrm{a}}$ \\
\cline { 2 - 5 } & Modified Goldberg Score & $0 \pm 0$ & $0.25 \pm 0.2$ & $3.9 \pm 0.1^{\mathrm{a}}$ \\
\hline
\end{tabular}




\section{2 weeks}
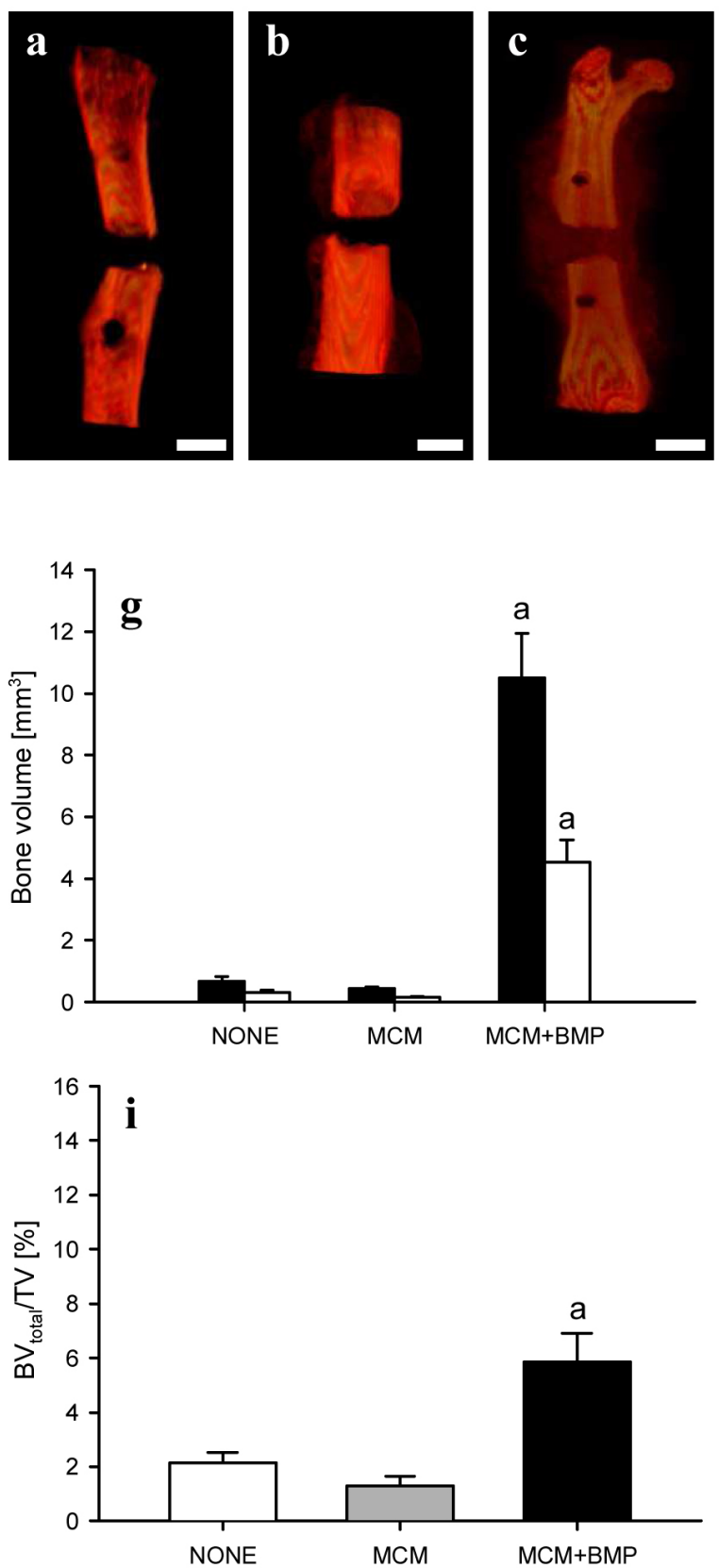

\section{0 weeks}
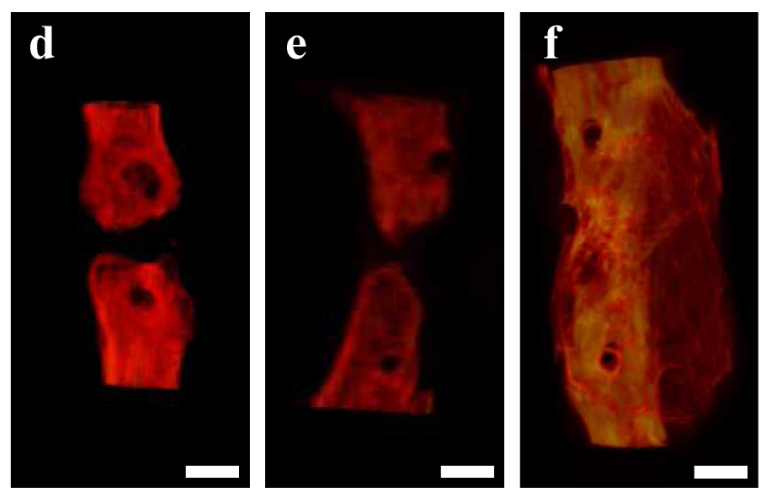
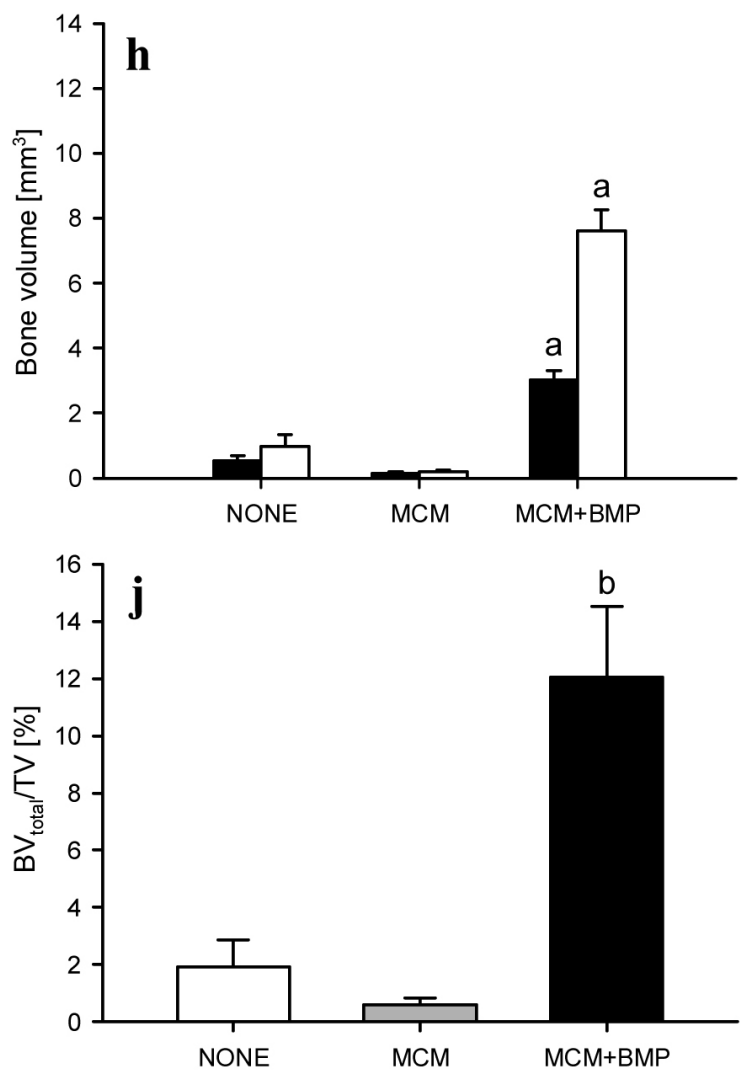

Fig. 4. $\mu \mathrm{CT}$ images of femurs at 2 weeks (a-c) and 10 weeks (d-f) after surgery of NONE (a,d), MCM (b,e) and MCM + BMP animals (c,f). Bars represent $1 \mathrm{~mm}$. Panels $\mathrm{g}$ and h display poorly (black bars) and highly (white bars) mineralised bone volume at (g) 2 weeks and (h) 10 weeks after surgery within the callus of NONE, MCM and MCM + BMP femurs. Panels $\mathbf{i}$ and $\mathbf{j}$ display the ratio total bone volume/tissue volume at (i) 2 weeks and (j) 10 weeks after surgery of NONE, MCM and MCM+BMP femurs. Mean \pm SEM; a $p<0.05 v s$. NONE and MCM; b $p<0.05 v s$. MCM.

In line with a previous in vitro study and comparable to optimal drug delivery systems using other techniques, the binding efficiency and the release kinetics of the MCM used in the present study were as expected (Yu et al., 2014; Babu et al., 2008; Carrasquillo et al., 2001). The incorporation of growth factors is a crucial factor for delivery strategies. Complicated processes and storagerelated stresses used in other approaches can lead to loss of protein activity (Suárez-González et al., 2012). The binding protocol in the present study only involved a simple buffer incubation. Previous studies could show that protein binding on mineral coatings proceeds through electrostatic interactions between the calcium phosphate mineral surface and the side chains on proteins as well as through the nano-porous structure of the MCM (Luong et al., 2006; Kandori et al., 2004; Xia et al., 2012; Ginebra et al., 2012). Especially the large surface area of the MCM allows for an efficient binding of the growth factor, while the binding protocol itself is technically easy, standardised and reproducible.

The ionic composition of MCM can be modified, resulting in a different stability and a different release 


\section{2 weeks}
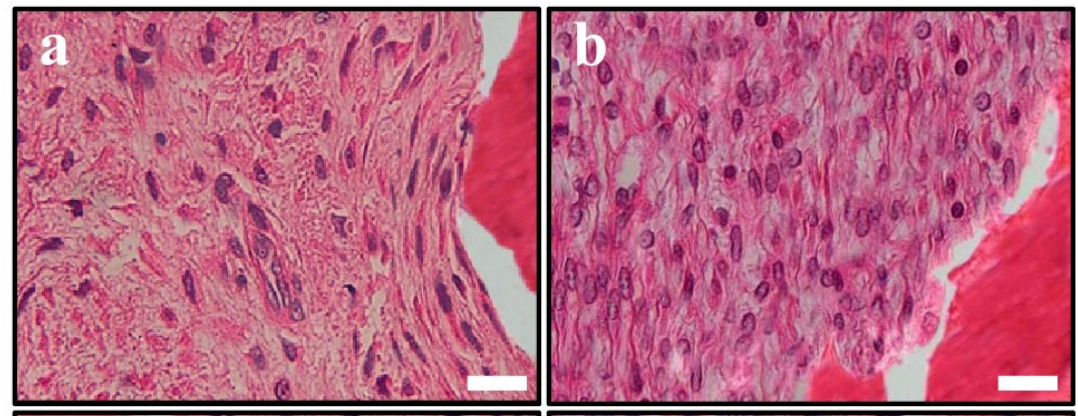

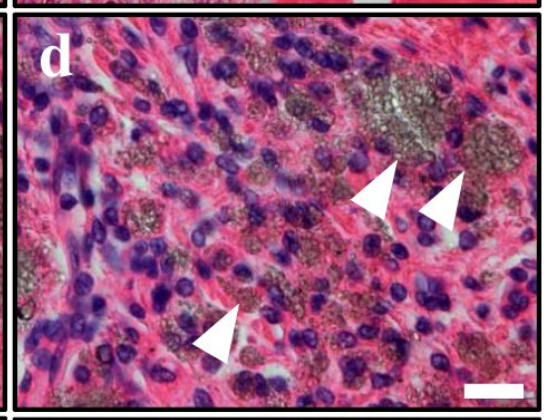

Fig. 5. HE staining of interfragmentary tissue of femurs of NONE $(\mathbf{a}, \mathbf{b}), \mathrm{MCM}$ $(\mathbf{c}, \mathbf{d})$ and $\mathrm{MCM}+\mathrm{BMP}$ group $(\mathbf{e}, \mathbf{f})$ at 2 weeks $(\mathbf{a}, \mathbf{c}, \mathbf{e})$ and 10 weeks $(\mathbf{b}, \mathbf{d}, \mathbf{f})$ after surgery. Note that microparticles (arrowheads) can be found at 2 weeks as well as at 10 weeks in femurs of the $\mathrm{MCM}$ and $\mathrm{MCM}+\mathrm{BMP}$ group (c-f). Of interest, microparticles showed some aggregation, resulting in conglomerates with a size of up to $30 \mu \mathrm{m}$. In contrast, the interfragmentary tissue of NONE femurs did not contain microparticles (a,b). Bars represent $20 \mu \mathrm{m}$.
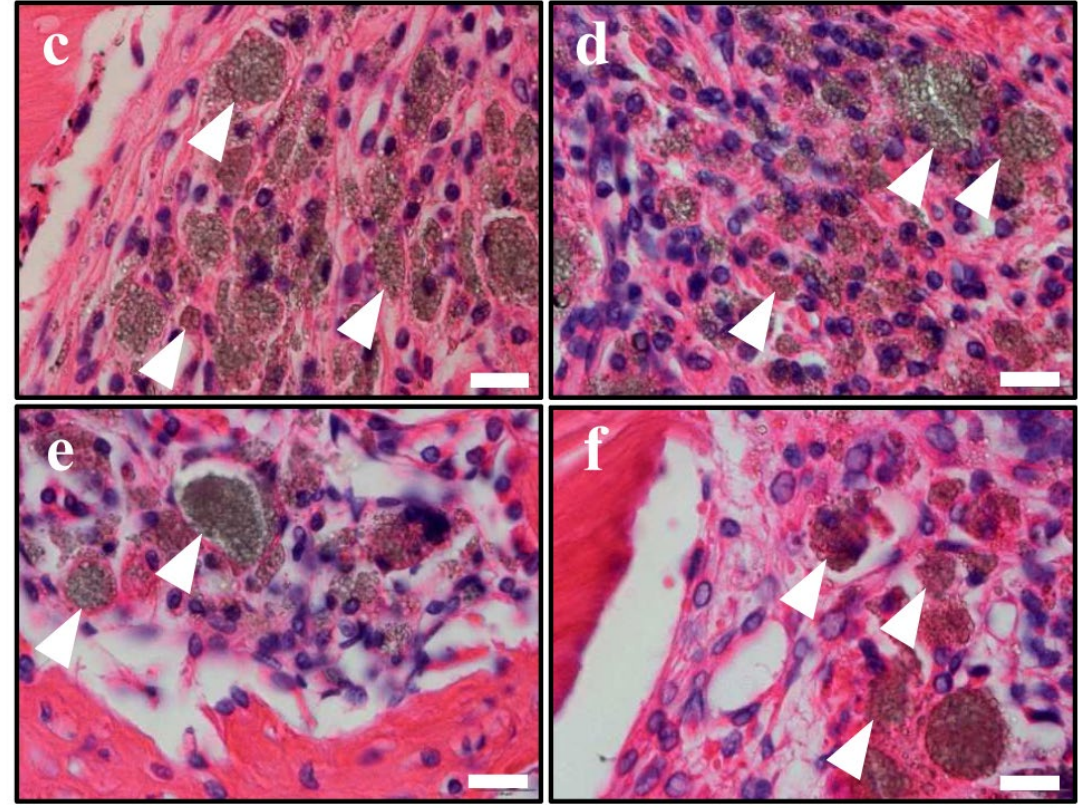

kinetic (Yu et al., 2014). In the present study, we used a carbonate concentration of $4.2 \mathrm{mM}$. According to $\mathrm{Yu}$ et al. (2014) this concentration reduces the release of BMP-2 within the first $30 \mathrm{~d}$ when compared to a higher concentration of $100 \mathrm{mM} \mathrm{HCO}_{3}^{-}$. On the other hand, $\mathrm{MCM}$ containing a lower carbonate concentration show a higher binding efficiency and a reduced calcium release, indicating a higher stability of the MCM. Because non-unions in mice are defined by a lack of healing over a 10 weeks period (Garcia et al., 2008a; Manigrasso and O'Connor, 2004), we have chosen an experimental observation period of 10 weeks. Because of this long in vivo experimental setup, we used MCM with the lower carbonate concentration in the present setting. We felt that these MCM are more suitable for our study due to their higher stability and their prolonged release kinetics.

As described by Yu et al. (2014) and confirmed by our results, BMP-2 showed a minor burst release in vitro within the first days, when MCM were single-coated. Taking into account the results of our in vivo study 2 weeks postoperatively, this supports the hypothesis that non-union formation is due to a reduced expression of osteogenic growth factors such as e.g. BMP-2/-4/-6/-7 during the early stage of bone healing (Mi et al., 2013; Cheng et al., 2003; Tsuij et al., 2006; Schmidmaier et al., 2002; Garcia et al., 2012; Schwabe et al., 2014). Although we do not have any data on BMP-2 release from MCM in vivo, our study demonstrates for the first time that the release of BMP-2 from MCM generates healing in a challenging non-union model. In this context it is noteworthy that MCM, after incorporation of growth factors, are of jelly-like consistency. This facilitates the application to a fracture site by direct, X-ray-controlled injection or other minimal invasive procedures instead of requiring further surgery for application. On the other hand, this consistency guarantees the continuance in position of application, as also confirmed in the present study.

In the present pin-clip model, the creation of a $1.8 \mathrm{~mm}$ bone defect combined with periosteal stripping representing the group NONE showed a non-union rate of $100 \%$ and, thus, served as an internal control of the murine model used in this study. These findings confirmed previous results using this model (Garcia et al., 2008a; Garcia et al., 2008b; Garcia et al., 2012; Holstein et al., 2009; Holstein et al., 2011; Histing et al., 2009; Histing et al., 2011). In contrast, MCM + BMP treatment induced osseous bridging already after 2 weeks. While biomechanical stability was still low at this early time point, MCM + BMP resulted in complete bridging with highly mineralised bone and, accordingly, in a markedly improved biomechanical stability after 10 weeks. The fact that MCM + BMP showed a reduced total callus area and total bone volume at 10 weeks compared to 2 weeks may be interpreted as adequate bone healing, including the process of remodelling, which 


\section{2 weeks}
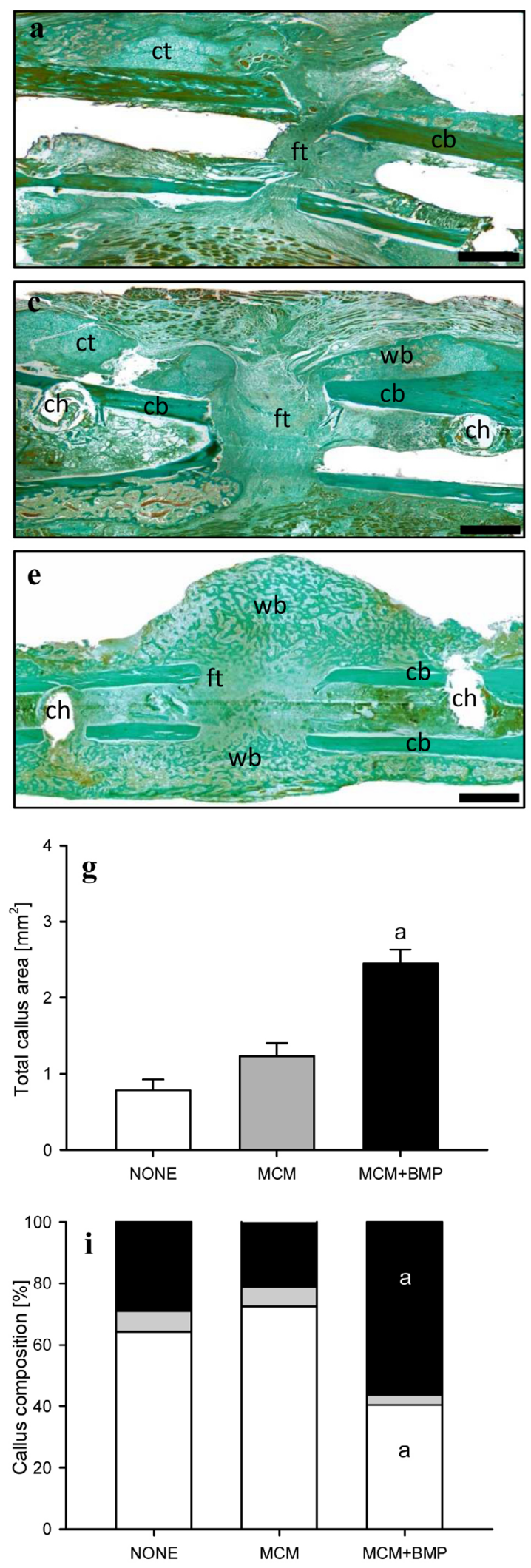

10 weeks
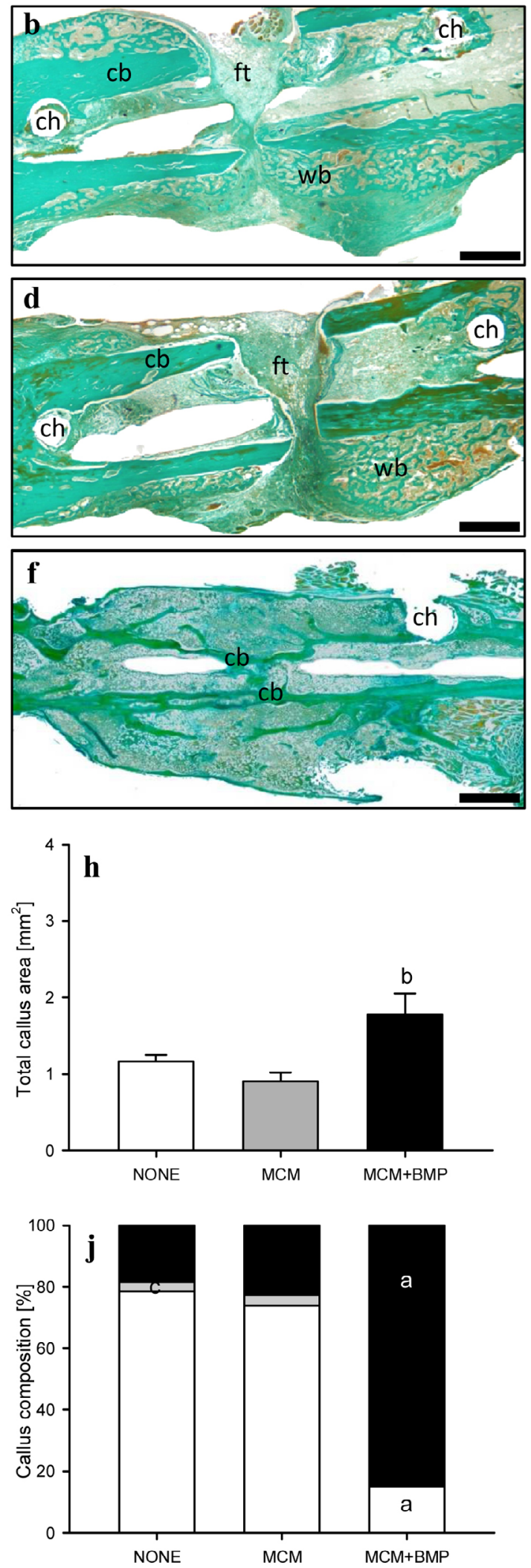

Fig. 6. Histological images after trichrome Masson Goldner staining of femurs at 2 weeks (a,c,e) and 10 weeks $(\mathbf{b}, \mathbf{d}, \mathbf{f})$ after surgery of NONE (a,b), MCM (c,d) and MCM + BMP animals (e,f). Fibrous tissue (ft), cartilage tissue (ct), woven bone (wb) and cortical bone (cb) are indicated. The drilling holes of the clip are indicated by ch. Bars represent $500 \mu \mathrm{m}$. Panels $\mathbf{g}$ to $\mathbf{j}$ display the total callus area $(\mathbf{g}, \mathbf{h})$ and the callus composition $(\mathbf{i}, \mathbf{j})$, including fibrous tissue (white), cartilage tissue (grey) and osseous tissue (black) of NONE, MCM and MCM + BMP femurs at 2 weeks (g,i) and 10 weeks $(\mathbf{h}, \mathbf{j})$ after surgery. Mean $\pm \mathrm{SEM} ;{ }^{\mathrm{a}} \mathrm{p}<0.05$ vs. NONE and MCM; ${ }^{\mathrm{b}} p<0.05$ vs. MCM; ${ }^{\mathrm{c}} p<0.05$ vs. MCM + BMP. 
2 weeks

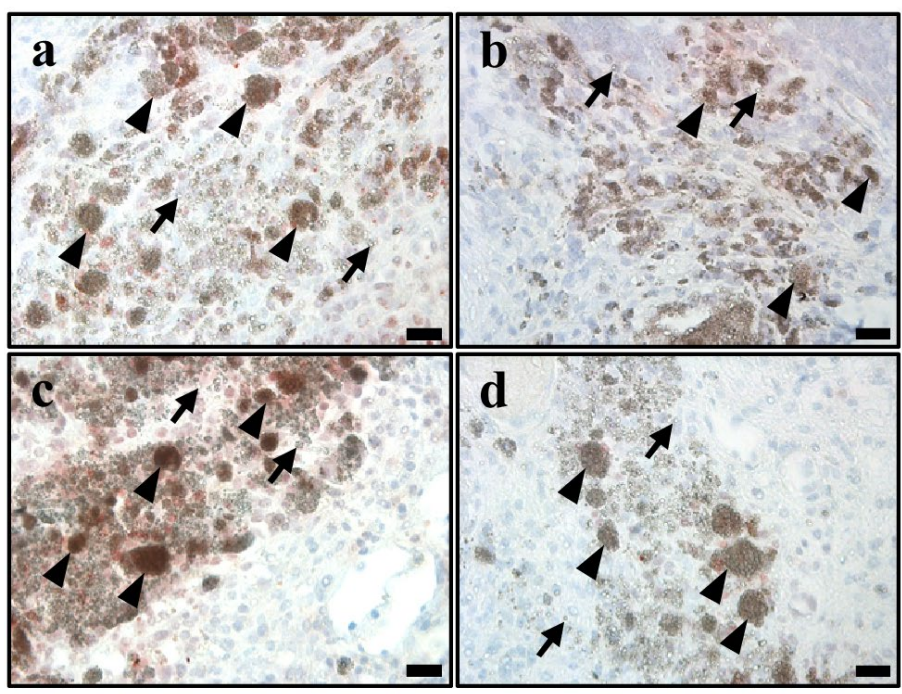

Fig. 7. Immunohistochemical F4/80 staining of macrophages within the interfragmentary tissue of femurs at 2 weeks $(\mathbf{a}, \mathbf{c})$ and 10 weeks $(\mathbf{b}, \mathbf{d})$ after surgery of MCM $(\mathbf{a}, \mathbf{b})$ and MCM $+\operatorname{BMP}(\mathbf{c}, \mathbf{d})$ animals. Note the lack of infiltrated macrophages in direct vicinity to MCM (arrows) and MCM aggregates (arrowheads), indicating a good biocompatibility. Images $\mathbf{e}$ and $\mathbf{f}$ show a positive (e, alveolar macrophages marked by arrows) and a negative control (f) for F4/80 staining of murine lung tissue. Bars represent $20 \mu \mathrm{m}$ (a-e) and $10 \mu \mathrm{m}$ (f).

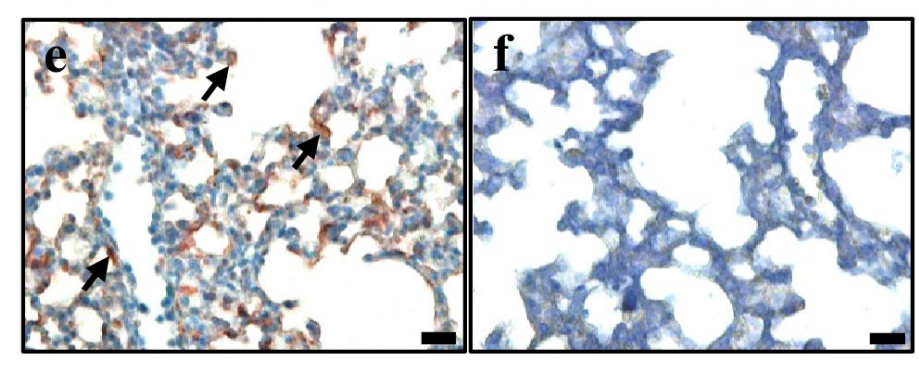

is characteristic for the late stage of bone repair (Schindeler et al., 2008; Hankenson et al., 2014).

The dosage of BMP-2 used in rodent animal models varies (Saito et al., 2003; Schmidmaier et al., 2002; Kanczler et al., 2010). However, the dosage necessary to improve bone repair is not elucidated yet and may depend on the route of application and the use of the carrier system. In the present study the in vivo application of MCM + BMP, containing $27.4 \mu \mathrm{g}$ BMP-2 per mouse, was successful to prevent the formation of a non-union by significantly increasing the size of the callus, the bone volume and the bending stiffness. According to the aforementioned release kinetics, we assumed a release of $8.5 \mu \mathrm{g}$ of BMP2 within the first $7 \mathrm{~d}$ and a release of $13.7 \mu \mathrm{g}$ BMP-2 within the first $30 \mathrm{~d}$. Compared to other studies using BMP-2 in vivo we actually applied a rather small amount of active BMP-2 at the fracture site. However, our results show that the amount of BMP-2 was obviously sufficient and might even be reduced further in follow-up studies. Particularly in view of a potential clinical application, this may markedly contribute to reduce costs and to minimise potential adverse effects, which have been reported for high dosages of BMP-2, such as heterotopic bone formation, immunological reactions and oedema (Gottfried and Dailey, 2008; Villavicencio et al., 2005). In these cases, it is necessary to reduce the dosage of the growth factor to a minimum. Besides, it is possible to apply MCM by direct injection or other minimal invasive procedures instead of requiring further surgery for application, which reduces the risk of surgery-related complications as well as surgeryrelated costs.

\section{Conclusions}

The use of MCM in bone healing has a great potential due to their ability to be tailored according to individual needs. In the present study MCM were tested for the first time in vivo. MCM coated with BMP-2 induced complete healing of atrophic non-unions in mice. Thus, MCM as a carrier and release system for BMP-2 should be of greatest interest for the treatment of delayed fracture healing and non-unions in clinical practice.

\section{Acknowledgements}

We greatly thank Janine Becker and Julia Parakenings for their excellent technical assistance.

\section{References}

Babu VR, Patel P, Mundargi RC, Rangaswamy V, Aminabhavi TM (2008) Developments in polymeric devices for oral insulin delivery. Expert Opin Drug Deliv 5: 403-415.

Bauer TW, Muschler GF (2000) Bone graft materials. An overview of the basic science. Clin Orthop Relat Res 371: 10-27.

Bosemark P, Isaksson H, McDonald MM, Little G, Tägil M (2013) Augmentation of autologous bone graft by a combination of bone morphogenic protein and 
bisphosphonate increased both callus volume and strength. Acta Orthop 84: 106-111.

Burdick JA, Mason MN, Hinman AD, Thorne K, Anseth KS (2002) Delivery of osteoinductive growth factors from degradable PEG hydrogels influences osteoblast differentiation and mineralisation. J Control Release 83: 53-63.

Carrasquillo KG, Stanley AM, Aponte-Carro JC, De Jésus P, Costantino HR, Bosques CJ, Griebenow K (2001) Non-aqueous encapsulation of excipient-stabilised spray-freeze dried BSA into poly(lactide-co-glycolide) microspheres results in release of native protein. J Control Release 76: 199-208.

Cheng H, Jiang W, Phillips FM, Haydon RC, Peng Y, Zhou L, Luu HH, An N, Breyer B, Vanichakarn P, Szatkowski JP, Park JY, He TC (2003) Osteogenic activity of the fourteen types of human bone morphogenetic proteins (BMPs). J Bone Joint Surg Am 85: 1544-1552.

Einhorn TA (2003) Clinical applications of recombinant human BMPs: early experience and future development. J Bone Joint Surg Am 85: 82-88.

Einhorn TA, Gerstenfeld LC (2015) Fracture healing: mechanisms and interventions. Nat Rev Rheumatol 11: 45-54.

Garcia P, Holstein JH, Maier S, Schaumlöffel H, AlMarrawi F, Hannig M, Pohlemann T, Menger MD (2008a) Development of a reliable non-union model in mice. J Surg Res 147: 84-91.

Garcia P, Holstein JH, Histing T, Burkhardt M, Culemann U, Pisanis A, Wirbel RJ, Pohlemann T, Menger MD (2008b) A new technique for internal fixation of femoral fractures in mice: impact of stability on fracture healing. J Biomech 41: 1689-1696.

Garcia P, Pieruschka A, Klein M, Tami A, Histing T, Holstein JH, Scheuer C, Pohlemann T, Menger MD (2012) Temporal and spatial vascularisation patterns of unions and non-unions: role of vascular endothelial growth factor and bone morphogenetic proteins. J Bone Joint Surg Am 94: 49-58.

Gazit D, Turgeman G, Kelley P, Wang E, Jalenak M, Zilberman Y, Moutsatsos I (1999) Engineered pluripotent mesenchymal cells integrate and differentiate in regenerating bone: a novel cell-mediated gene therapy. J Gene Med 1: 121-133.

Gerstenfeld LC, Wronski TJ, Hollinger JO, Einhorn TA (2005) Application of histomorphometric methods to the study of bone repair. J Bone Miner Res 20: 1715-1722.

Ghosh P, Han G, De M, Kim CK, Rotello VM (2008) Gold nanoparticles in delivery applications. Adv Drug Deliv Rev 60: 1307-1315.

Ginebra MP, Canal C, Espanol M, Pastorino D, Montufar EB (2012) Calcium phosphate cements as drug delivery materials. Adv Drug Deliv Rev 64: 1090-1110.

Gottfried ON, Dailey AT (2008) Mesenchymal stem cell and gene therapies for spinal fusion. Neurosurgery 63: $380-391$.

Hankenson KD, Zimmerman G, Marcucio R (2014) Biological perspectives of delayed fracture healing. Injury 45: 8-15.
Histing T, Holstein JH, Garcia P, Matthys R, Kristen A, Claes L, Menger MD, Pohlemann T (2009) Ex vivo analysis of rotational stiffness of different osteosynthesis techniques in mouse femur fracture. J Orthop Res 27: 1152-1156.

Histing T, Garcia P, Holstein JH, Klein M, Matthys R, Nuetzi R, Steck R, Laschke MW, Wehner T, Bindl R, Recknagel S, Stuermer EK, Vollmar B, Wildemann B, Lienau J, Willie B, Peters A, Ignatius A, Pohlemann T, Claes L, Menger MD (2011) Small animal bone healing models: standards, tips, and pitfalls results of a consensus meeting. Bone 49: 591-599.

Histing T, Heerschop K, Klein M, Scheuer C, Stenger D, Holstein JH, Pohlemann T, Menger MD (2016) Characterisation of the healing process in non-stabilised and stabilised femur fractures in mice. Arch Orthop Trauma Surg 136: 203-211.

Holstein JH, Garcia P, Histing T, Kristen A, Scheuer C, Menger MD, Pohlemann T (2009) Advances in the establishment of defined mouse models for the study of fracture healing and bone regeneration. J Orthop Trauma 23: 31-38.

Holstein JH, Orth M, Scheuer C, Tami A, Becker SC, Garcia P, Histing T, Mörsdorf P, Klein M, Pohlemann T, Menger MD (2011) Erythropoietin stimulates bone formation, cell proliferation, and angiogenesis in a femoral segmental defect model in mice. Bone 49: 1037-1045.

Huang YH, Polimeni G, Qahash M, Wikesjö UM (2008) Bone morphogenetic proteins and osseointegration: current knowledge-future possibilities. Periodontol 2000 47:206223.

Isaksson H, Gröngröft I, Wilson W, van Donkelaar CC, van Rietbergen B, Tami A, Huiskes R, Ito K (2009) Remodelling of fracture callus in mice is consistent with mechanical loading and bone remodelling theory. J Orthop Res 27: 664-672.

Kanczler JM, Oreffo RO (2008) Osteogenesis and angiogenesis: the potential for engineering bone. Eur Cell Mater 15: 100-114.

Kanczler JM, Ginty PJ, White L, Clarke NM, Howdle SM, Shakesheff KM, Oreffo RO (2010) The effect of the delivery of vascular endothelial growth factor and bone morphogenic protein-2 to osteoprogenitor cell populations on bone formation. Biomaterials 31: 1242-1250.

Kandori K, Miyagawa K, Ishikawa T (2004) Adsorption of immunogamma globulin onto various synthetic calcium hydroxyapatite particles. J Colloid Interface Sci 273: 406413.

King WJ, Krebsbach PH (2012) Growth factor delivery: how surface interactions modulate release in vitro and in vivo. Adv Drug Deliv Rev 64: 1239-1256.

Kloen P, Di Paola M, Borens O, Richmond J, Perino G, Helfet DL, Goumans MJ (2003) BMP signaling components are expressed in human fracture callus. Bone 33: $362-371$.

Kwong FN, Hoyland JA, Freemont AJ, Evans CH (2009) Altered relative expression of BMPs and BMP inhibitors in cartilaginous areas of human fractures progressing towards non-union. J Orthop Res 27: 752-757. 
Luong LN, Hong SI, Patel RJ, Outslay ME, Kohn DH (2006) Spatial control of protein within biomimetically nucleated mineral. Biomaterials 27: 1175-1186.

Manigrasso MB, O’Connor JP (2004) Characterisation of a closed femur fracture model in mice. J Orthop Trauma 18: $687-695$.

Megas P (2005) Classification of non-union. Injury 36: 30-37.

Mi M, Jin H, Wang B, Yukata K, Sheu TJ, Ke QH, Tong P, Im HJ, Xiao G, Chen D (2013) Chondrocyte BMP2 signalling plays an essential role in bone fracture healing. Gene 512: 211-218.

Morgan EF, Mason ZD, Chien KB, Pfeiffer AJ, Barnes GL, Einhorn TA, Gerstenfeld LC (2009) Micro-computed tomography assessment of fracture healing: relationships among callus structure, composition, and mechanical function. Bone 44: 335-344.

Saito N, Okada T, Horiuchi H, Ota H, Takahashi J, Murakami N, Nawata M, Kojima S, Nozaki K, Takaoka K (2003) Local bone formation by injection of recombinant human bone morphogenetic protein-2 contained in polymer carriers. Bone 32: 381-386.

Schindeler A, McDonald MM, Bokko P, Little DG (2008) Bone remodelling during fracture repair: the cellular picture. Semin Cell Dev Biol 19: 459-466.

Schmidmaier G, Wildemann B, Cromme F, Kandziora F, Haas NP, Raschke M (2002) Bone morphogenetic protein-2 coating of titanium implants increases biomechanical strength and accelerates bone remodelling in fracture treatment: a biomechanical and histological study in rats. Bone 30: 816-822.

Schwabe P, Simon P, Kronbach Z, Schmidmaier G, Wildemann B (2014) A pilot study investigating the histology and growth factor content of human non-union tissue. Int Orthop 38: 2623-2629.

Suárez-González D, Lee JS, Lan Levengood SK, Vanderby R Jr, Murphy WL (2012) Mineral coatings modulate $\beta$-TCP stability and enable growth factor binding and release. Acta Biomater 8: 1117-1124.

Suárez-González D, Lee JS, Diggs A, Lu Y, Nemke B, Markel M, Hollister SJ, Murphy WL (2014) Controlled multiple growth factor delivery from bone tissue engineering scaffolds via designed affinity. Tissue Eng Part A 20: 2077-2087.

Tang S, Zhao J, Xu S, Li J, Teng Y, Quan D, Guo X (2012) Bone induction through controlled release of novel BMP-2-related peptide from PTMC $11-F 127-$ PTMC $_{11}$ hydrogels. Biomed Mater 7: 015008.

ten Dijke P (2006) Bone morphogenetic protein signal transduction in bone. Curr Med Res Opin 22: 7-11.

Tsuji K, Bandyopadhyay A, Harfe BD, Cox K, Kakar S, Gerstenfeld L, Einhorn T, Tabin CJ, Rosen V (2006) BMP2 activity, although dispensable for bone formation, is required for the initiation of fracture healing. Nat Genet 38: 1424-1429.

Turgeman G, Pittman DD, Müller R, Kurkalli BG, Zhou S, Pelled G, Peyser A, Zilberman Y, Moutsatsos IK, Gazit D (2001) Engineered human mesenchymal stem cells: a novel platform for skeletal cell mediated gene therapy. J Gene Med 3: 240-251.
Villavicencio AT, Burneikiene S, Nelson EL, Bulsara KR, Favors M, Thramann J (2005) Safety of transforaminal lumbar interbody fusion and intervertebral recombinant human bone morphogenetic protein-2. J Neurosurg Spine 3: 436-443.

Xia Z, Yu X, Wei M (2012) Biomimetic collagen/apatite coating formation on Ti6Al4V substrates. J Biomed Mater Res B Appl Biomater 100: 871-881.

Yoneda M, Terai H, Imai Y, Okada T, Nozaki K, Inoue H, Miyamoto S, Takaoka K (2005) Repair of an intercalated long bone defect with a synthetic biodegradable boneinducing implant. Biomaterials 26: 5145-5152.

Yu X, Khalil A, Dang PN, Alsberg E, Murphy WL (2014) Multilayered inorganic microparticles for tunable dual growth factor delivery. Adv Funct Mater 24: 30823093.

Zegzula HD, Buck DC, Brekke J, Wozney JM, Hollinger JO (1997) Bone formation with use of rhBMP-2 (recombinant human bone morphogenetic protein-2). J Bone Joint Surg Am 79: 1778-1790.

\section{Discussion with Reviewers}

Mattiew Stewart: The missing group in this study was an atrophic non-unions receiving BMP-2 without MCM (BMP - MCM). Given the rapid elution of rhBMP-2 from the scaffold material used currently in practice and the impressive osteogenic activity of this product, what response do the authors think they would have seen in this group? How close to the MCM + BMP?

Authors: The major problem of analysing BMP - MCM is the fact that rhBMP-2 cannot be selectively applied to the bone defect, but is also distributed in the surrounding soft tissue due to its liquid consistency. Therefore, it is also not possible to guarantee a standardised growth factor concentration within the bone defect throughout the observation period of the experiment. In addition, it is well known that BMP-2 should not only be present for a short time in the fracture gap, but should continuously stimulate bone formation to exert a maximal positive effect on fracture healing (ten Dijke et al., 2006). Based on these facts, it may be assumed that BMP - MCM would not induce an osseous bridging of the bone defect in contrast to the group MCM + BMP. Moreover, the uncontrolled distribution of liquid rhBMP-2 within the surrounding soft tissue may further induce ectopic bone formation without any functional benefits and increase the risk of BMP-2 side effects, such as immunological reactions and oedema formation (Gottfried and Dailey, 2008).

Chris Evans: It would have been interesting if a group of mice with defects and treated with a conventional BMP-2 delivery system (e.g. collagen sponge) had been included. Maybe the team has historical data for this?

Authors: We agree with the reviewer that it would have been interesting to compare our MCM + BMP group with a group receiving a conventional BMP-2 delivery system. However, we have no historical data for this. As indicated by the reviewer, collagen sponges are widely accepted 
and used as carrier systems for BMP-2 in experimental studies. However, they bear the disadvantage that their BMP-2 release rates are quite high during the initial days after implantation. For instance, Yang et al. (2011) reported that non-coated collagen scaffolds exhibit a total release of $98 \pm 2 \%$ of the bound BMP-2 within only $24 \mathrm{~h}$. In contrast, the herein studied MCM are electrolyte-coated hydroxyapatite particles, which allow a more sustained release of BMP-2 over longer time periods. This is a major advantage given the fact that BMP-2 should not only be present for a short time in the fracture gap, but should continuously stimulate bone formation to exert a maximal positive effect on fracture healing (ten Dijke et al., 2006). Based on these findings, it may be assumed that in the present experimental setting conventional BMP-2-coated collagen scaffolds would not induce an osseous bridging of the bone defect in contrast to the group MCM + BMP.

Chris Evans: The total dose of BMP-2 delivered to each defect is $27.4 \mu \mathrm{g}$. This seems very high.

Authors: We do not feel that our BMP-2 dose was very high when compared to other studies. In fact, given a total release from the MCM of only $62 \%$ of the initially bound BMP-2 within the first $60 \mathrm{~d}$, the bone defects were treated with an effective dose of $17 \mu \mathrm{g}$ BMP-2. In comparison, Kanczler et al. (2010) used a total dose of $20 \mu \mathrm{g}$ BMP-2 in combination with vascular endothelial growth factor (VEGF) to improve bone healing in a non-union mouse model. By this, they observed a significant increase of bone volume, but, in contrast to our results, no osseous bridging of the bone defects. These discrepant findings may be explained by the fact that the MCM used in our study allowed a more sustained release of BMP-2. The proven effectiveness of our approach raises the question, if the dosage of BMP-2 to induce osseous bridging can be even further reduced in the present experimental setting. We plan to study this in additional follow-up studies.

Chris Evans: Fig. 6 e,f shows no cartilage at 2 or 10 weeks. Does this suggest that healing is intramembranous?

Authors: Our histomorphometric analyses revealed that cartilage formation was reduced in the group MCM
+ BMP at 2 weeks after surgery when compared to the other two groups (Fig. 6i). Moreover, cartilage tissue was not detectable anymore in the group MCM + BMP at 10 weeks after surgery (Fig. 6j). Taken together, these findings indicate that the healing of the bone defect was markedly accelerated in this group when compared to the other groups. Nonetheless, we feel that the healing of the bone most probably occurred as a mixture of intramembranous and endochondral ossification. This view is supported by the results of other studies, demonstrating that BMP-2 is capable of stimulating both, intramembranous as well as endochondral ossification (Stoeger et al., 2002; Kawai et al., 2005; De Santana et al., 2015).

\section{Additional References}

de Santana RB, Trackman PC (2015) Effect of targeted delivery of bone morphogenetic protein-2 on bone formation in type 1 diabetes. Int J Oral Maxillofac Implants 30: 707-714.

Kawai M, Bessho K, Maruyama H, Miyazaki J, Yamamoto T (2005) Human BMP-2 gene transfer using transcutaneous in vivo electroporation induced both intramembranous and endochondral ossification. Anat Rec A Discov Mol Cell Evol Biol 287: 1264-1271.

Stoeger T, Proetzel GE, Welzel H, Papadimitriou A, Dony C, Balling R, Hofmann C (2002) In situ gene expression analysis during BMP2-induced ectopic bone formation in mice shows simultaneous endochondral and intramembranous ossification. Growth Factors 20: 197210.

Yang HS, La WG, Bhang SH, Lee TJ, Lee M, Kim BS (2011) Apatite-coated collagen scaffold for bone morphogenetic protein-2 delivery. Tissue Eng Part A 17: 2153-2164.

Editor's note: The Scientific Editor responsible for this paper was Chris Evans. 